\title{
ESCLEROMALÁCIA SECUNDÁRIA À ARTRITE REUMATÓIDE: UM RELATO DE CASO
}

Ana Claudia Kurmann ${ }^{1}$, Alessandra Faggion Mocellin², Elisa Frana ${ }^{2}$, Emanuela Lando $^{2}$, Gabrielle Senter $^{3}$, Lhaís de Lima Zanotto ${ }^{2}$, Natani Menegolla ${ }^{2}$, Paola Dal Molin Felizola ${ }^{2}$, Thoany Pellizari² Thais Rohde Pavan ${ }^{4}$

${ }^{1}$ Acadêmica de medicina da Universidade de Passo Fundo (UPF)

2 Acadêmicas de medicina da Faculdade Meridional (IMED) ${ }^{3}$ Médica oftalmologista

${ }^{4}$ Médica reumatologista e professora de reumatologia da Universidade de Passo Fundo (UPF) e Instituto Meridional (IMED)

\section{INTRODUÇÃO}

A Artrite Reumatóide (AR) é uma doença autoimune de acometimento sistêmico caracterizada por poliartrite simétrica periférica ${ }^{1}$. O quadro inflamatório crônico em articulações apresenta-se na maioria dos casos, porém manifestações extra-articulares também podem estar associadas a doença. As manifestações oculares podem apresentar-se como ceratoconjuntivite, episclerite, esclerite, alterações da córnea e vasculite retiniana. Escleromalácia é uma forma grave e rara de esclerite necrotizante apresentada pelo tom azul e pelo afinamento progressivo da esclera ocular ${ }^{2}$.

\section{OBJETIVOS}

$\mathrm{O}$ presente relato visa discutir o caso de paciente portadora de AR de longa data, que desenvolveu manifestação oftalmológica rara da doença, a escleromalácia.

\section{RELATO DO CASO}

Paciente feminina, 40 anos, portadora de AR desde os 17 anos, com deformidades em mãos, punhos e pés, fator reumatoide 512, em uso de metotrexate $20 \mathrm{mg}$ por semana, ácido fólico $5 \mathrm{mg}$ por semana e predinisona 10mg ao dia. Em consulta com oftalmologista por queixa de xeroftalmia, observou-se aspecto escurecido em volta da córnea e afinamento da esclera, achados compatíveis com escleromalácia. Diante do quadro, o tratamento foi otimizado, com associação de terapia antiTNF.

\section{DISCUSSÃO}

A esclerite é uma doença inflamatória, dolorosa e que pode levar à cegueira, caracterizada por edema e infiltrado celular inflamatório na esclera $^{3}$. É uma condição rara, afetando cerca de $6,3 \%$ dos pacientes com $\mathrm{AR}^{4}$. Dentre as formas de apresentação, a esclerite necrotizante sem inflamação (escleromalácia) é a mais ameaçadora e está relacionada com doenças autoimunes ${ }^{3}$.A escleromalácia possui prevalência pelo sexo feminino e tem relação com $\mathrm{AR}$ de longa duração ${ }^{4}$. Há presença de um arco em tom azul escuro ao redor da córnea, causado pelo afinamento da esclera $^{5}$. As consequências visuais são severas, sendo que a mais temida é a perfuração ${ }^{4,6}$. Não existe tratamento específico, sendo que a intensificação do tratamento da doença de base é recomendada ${ }^{3,4}$.

\section{CONCLUSÃO}

As manifestações oculares acometem cerca de $25 \%$ dos pacientes portadores de AR. As esclerites são mais prevalentes em indivíduos com doenças do tecido conjuntivo que na população em geral ${ }^{6}$. A escleromalácia, a forma mais severa da esclerite, é também a menos frequente $^{3}$. As complicações podem ser graves, incluindo a perfuração, sendo por isso necessário intensificar o tratamento da doença de base, uma vez que não existe tratamento específico ${ }^{3,4}$.

\section{REFERÊNCIAS}

1. American College of Rheumatology Subcommitte on Rheumatoid Arthritis Guidelines. Guidelines for the management of rheumatoid arthritis. Arthritis Rheum 46:328-46, 2002.

2. Tong L, Thumboo J, Tan YK, Wong TY, Albani S. The eye: a window of opportunity in rheumatoid arthritis? Nat Rev Rheumatol. 2014;10(9):552-60.2014 Epub 2014 Jun 10.

3. Gordana Zlatanović1, Dragan Veselinović2, Sonja Cekić3*, Maja Živković3, Jasmina Đorđević- Jocić4, Marko Zlatanović . Ocular manifestation of rheumatoid arthritis-different forms and frequency. BOSNIAN JOURNAL OF BASIC MEDICAL SCIENCES 2010; 10 (4): 323-327

4. Mathieu Artifoni, Pierre-Raphaël Rothschild, Antoine Brézin, Loïc Guillevin and Xavier Puéchal: Ocular inflammatory diseases associated with rheumatoid arthritis. Nature reviews: Reumathology. 2014. V. 10

5. Muhammad Ishaq Ghauri1, Syeda Urooj Riaz1*, Amir Husain2, Asad Raza Jafri3 and Zara Tul Ain Bashir1.: Scleromalacia perforans: a case report. Journal of Medical Case Reports (2018) 12:155.

6. Natalie A. Afshari, MD, Mehran A. Afshari, MD, MPH, and C. Stephen Foster, MD, FRCS: Inflammatory Conditions of the Eye Associated with Rheumatic Diseases. Current Rheumatology Reports 2001, 3:453-458

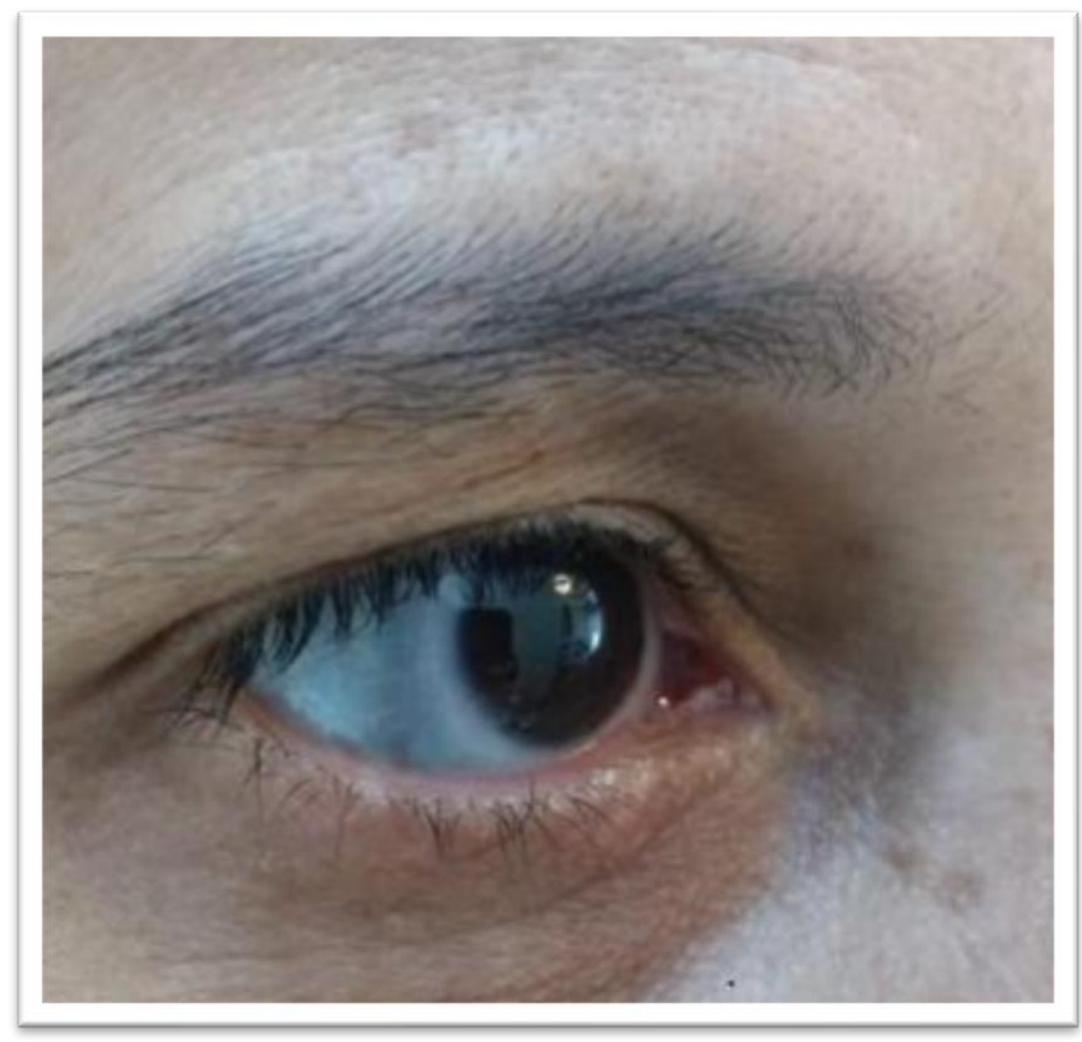

